\title{
The Construction and Cultivation of the Core Competencies of Business Teachers in the Background of New Business
}

\author{
Yi Liu*, Siping Peng, Panjia Chen
}

\author{
School of Business Administration, Neusoft Institute Guangdong \\ *Corresponding author. Email: liuyi@nuit.edu.cn
}

\begin{abstract}
The new business education is a new model business education under the background of the new business era, and is with characteristics of sociality, integration, applicability and openness. For business teachers in the new era, it is not only necessary to adhere to demand-oriented, goal-oriented, problem-oriented and development-oriented, but also to build a core competencies system and focus on cultivating core competencies, so that it is possible to adapt to the changes of the times and the requirements of new business. On the basis of the guidance and requirements of business teachers in the new era, constructing a "six-dimensional" core competencies system for business teachers in the new era, and proposing cultivation paths: introducing and fostering simultaneously to build a team of "double-qualified" teachers; collaborating government, school, enterprise and society to build a multi-subject network; putting equal emphasis on knowledge and ability, and establishing a diversified teacher evaluation system; inheriting and innovating simultaneously to improve teacher incentive mechanisms; cultivating innovative capabilities and strengthening social service awareness; guiding consciousness and habits as well as cultivating a lifelong learning culture.
\end{abstract}

Keywords: New Business, Business Teachers, Core Competencies, Construction, Cultivation

\section{INTRODUCTION}

In the new era, business education has stronger sociality, integration, application, and openness, and it also puts forward many new requirements for teachers, such as deeply understanding of social needs and strengthening practical experience, possessing compound knowledge and integrating cross-industry capabilities, focusing on business issues and emphasizing research and application, etc. The "Opinions on Comprehensively Deepening the Reform of the Construction of the Teaching Staff in the New Era" also clearly stated that the comprehensive quality, professionalism and innovation capabilities of teachers need to be greatly improved. The development of the core competencies of teachers is aimed at the professional construction of the teaching team. With the widespread dissemination and penetration of studentcentered educational theories, many teachers have blurred understanding of the boundaries of the development of teacher-student literacy, focusing on their own development to improve student literacy, but lacking a clear thinking about the core literacy and ability improvement of their own. In fact, the orientation of students in the career development of teachers is only one of the important goals. The development of teachers and students is affected by multiple dimensional factors such as their roles, status, methods and goals, and cannot be equivalently replaced [1]. Therefore, it is necessary to build a core competencies system for business teachers on the basis of understanding the connotation and characteristics of business education, and the new requirements for teachers in the new era, and further explore its cultivation paths.

\section{THE CONSTRUCTION OF THE CORE COMPETENCE SYSTEM OF BUSINESS TEACHERS IN THE NEW ERA}

Core abilities or key abilities refer to the abilities that are important to a person's learning, work, and development, and has a long-term impact. For teachers, core competencies play important supporting role in their learning, work and development process, and 
produces decisive effectiveness. Core competencies are not all competencies, but have the characteristics of small quantity, importance, contemporaneity, and matching [2].

Combining the connotation and characteristics of business education in the new era, the guidance and requirements for teachers, this article constructs a "sixdimensional" core competencies system of business teachers in the new era from the following six aspects.

\subsection{Social understanding}

Social understanding ability is the ability of teachers to understand the needs of social development and the results of social development, and the ability of teachers to understand the social background of educational development [2]. Business itself has a high degree of integration with society, and the new business education is derived from new technologies such as big data, artificial intelligence, cloud computing, and the background of business 3.0 such as consumption upgrades, sharing economy, and interconnection which is inseparable from the latest social development and dynamics. In the new era, business teachers must be able to connect education and society, as well as social development and students' personal development, in order to understand, plan, organize and implement specific education and teaching activities at the height of society and the country in the new era and new situation, to promote students' understanding and adaptation to society and social needs.

\subsection{Social connectivity}

Social connectivity refers to the ability that teachers guide students to fully understand and serve society, and at the same time enable students to accept the positive influence of society [2], and that teachers link social business practices with specific teaching and research activities by considering the practical characteristics of business education in the new era. This requires teachers to look at the business environment and business events from a comprehensive and dynamic perspective, and to teach business, economics, and management knowledge more closely and in-depth with business practices. On this basis, more scientific and effective platforms or channels should be used to help students build and improve their sense of social responsibility, social adaptability, and social service capabilities, so as to build a bridge for students in advance to connect the society before them actually enter the business environment and market. At the same time, the ability of social connectivity also requires teachers to treat a series of activities such as teaching, teaching research and scientific research with an open attitude, and strengthen the connection between educational activities and actual business activities.

\subsection{Knowledge integration capability}

In the new business construction with higher and higher integration requirements, it is obviously not enough for teachers to have traditional business knowledge. While possessing a systematic perspective and business thinking, familiar with the commercial market and its operating rules and practices, teachers with a complex knowledge background and abilities tend to have stronger competitiveness. This is because business education in the new era is more comprehensive and cross-cutting. In addition to its own economic management knowledge, it also integrates more technologies (such as mathematics and computing, information technology, management engineering, big data), humanities (such as literature and art, psychology, etc.) and other fields of content comprehensively involve people, things, skills, money, etc., which puts forward higher requirements for teachers' compound knowledge and ability. Under this situation, business teachers in the new era must break through knowledge barriers, continuously expand their scope of knowledge, and enhance the comprehensiveness of their ontological abilities such as logical thinking ability, communication ability, and cooperation ability.

\subsection{Social service capacity}

Serving the society is the third important function of universities after cultivating specialized talents and developing scientific knowledge, and it is also a core task that the construction of business in the new era attaches great importance to. In colleges and universities, teachers who are vital to the ability of colleges and universities to play this role should undoubtedly have the corresponding social service capability and regard it as a core competency. The reasons are mainly in the following aspects: Firstly, participate in schoolenterprise cooperation, and deepen the combination of work and study. Enterprise is an important part of society, and it is also an important connection object of business in the new era. In the process of cooperating with enterprises, teachers can use the theory of business in the new era to promote the development and progress of the industry, and the practice of enterprises can in turn spur the update of business theory. Secondly, focus on cultivating students based on actual needs. In the process of serving the society, teachers can more clearly understand the needs of the company for future employees, recognize the difference between the level of social needs and the level of student development, and urge teachers to train students' knowledge and ability in a targeted manner. Thirdly, strengthen selfreflection and improve professionalism. Serving the society is not only a contribution, but also a gain. This is because while serving the society, teachers can update and match their existing technology and business knowledge in a timely manner by observing the real 
business world. The improvement of professionalism is of great help. In the process of exploring ways to improve social service capabilities, universities and teachers need to adhere to the principle of diversification, and feed the final results back to teachers' teaching, teaching research, scientific research, and talent training.

\subsection{Creativity}

Creativity is a broad concept with a large extension [1]. It has covered more content in previous research. Under the research background of this article, the creativity of business teachers in the new era is mainly reflected in teaching innovation, scientific research innovation and ransformation of innovation achievements [3]. Business education in the new era is supported by certain information technology, so teachers need to apply constantly updated information technology to the teaching process, integrate educational information and innovate in teaching content, methods, models, evaluation and other aspects to improve teaching effect. In terms of scientific research, based on their attention to specific business issues, teachers infiltrate the problem-solving goals into the topic and purpose of scientific research, creatively discover and solve problems, and emphasize research applications. Finally, use the results of teaching and scientific research to transform them into actual productivity and influence, innovate the methods and paths in the transformation process, and improve transformation efficiency and transformation effects.

\subsection{Lifelong learning ability}

Lifelong learning ability refers to a kind of selflearning ability that people have in order to adapt to social development and realize the needs of individual development which is specifically expressed as a function and activity of the brainilit and enables people to analyze the objective environment and laws. Moreover, the objective environment of the learner has a great influence on the improvement of lifelong learning ability. The business world is changing rapidly and changing with each passing day. The technology, business rules, and systems involved are undergoing continuous changes, that is, "biggest change is change". In this environment, it is only possible for business teachers in the new era to respond to changes in time, embrace changes who have the ability to learn for life, so as to continue to learn in the process of educational practice, acquire and master knowledge and skills through continuous independent learning [1], and at the same time continue to tap their own potential, so as to acquire enough knowledge to adapt to social development, not only limited to the current education and development, but also facing the future. It should be pointed out that lifelong learning ability plays a certain role in promoting the aforementioned five abilities.

\section{THE CULTIVATION PATHS OF THE CORE COMPETENCIES OF BUSINESS TEACHERS IN THE NEW ERA}

\subsection{Simultaneous introduction and cultivation to build a team of "double-qualified" teachers}

Creating economic value to serve the society is one of the basic functions of colleges and universities, and building a team of "double-qualified" teachers is an important means for colleges and universities to achieve their mission. As mentioned above, business teachers in the new era must be well aware of social needs, strengthen practical experience, focus on business issues, emphasize research and application, and teachers who have only professional theoretical knowledge but lack industry practice capabilities and practical experience cannot meet the needs of business practice environment and activities and the requirements of the new era. For the construction of business teachers in the new era, "bringing in" and "going out" can be carried out at the same time. The former is the introduction and the latter is the cultivation. On the one hand, directly introduce teachers with industry and enterprise experience, on the other hand, cultivate existing teachers, specifically, domestic and foreign school visits, on-the-job training and other social practice systems can be adopted, and the "one lesson, two teachers" model can also be considered. The corporate tutors and school teachers jointly serve as course teachers, with division of labor and collaboration. In the process of jointly completing teaching tasks, school teachers can more directly and efficiently absorb new knowledge, new technology, new requirements and new trends in the current industry and market, and integrate them into the follow-up teaching process and optimize ontinuously.

\subsection{Collaboration between government, school, industry, enterprise and society to build a multi- subject connectivity network}

The integration of production and education is an important way to promote the effective connection between education and industry. The deep integration of industry and education lies in innovating the cooperative school running mechanism, building a diversified school running pattern, perfecting the job demandoriented talent training model, and realizing the organic integration of the education chain, the talent chain, the industrial chain, and the innovation chain [4]. As the main body of a community with a shared future, the "government, school, industry, enterprise and society" are in the same social network. Through guidance and institutional arrangements, it promotes network 
members to play their respective abilities and advantages, integrate complementary resources, realize the complementary advantages of all parties, and achieve synergistic effects. Given the established resources and environmental conditions, it is conducive to the quality and improvement of talent training in the new era. In this process, through the construction of a multi-agent interconnection network, the teacher network node can better link with other nodes in the overall network, so as to obtain and update their own knowledge in a timely manner, and optimize the knowledge structure in the network interconnection and intercommunication, and enhance capacity reserves.

\subsection{Paying equal attention to knowledge and ability and establishing a diversified teacher evaluation system}

Educational evaluation has appraisal function, guiding function, incentive function, diagnosis function, adjustment function, supervision function, management function, and education function. It is an important link in the entire chain of education reform and development [5]. The function of educational evaluation is embodied by the effect of educational evaluation activities and results on the evaluation objects, and the content of its functions depends on the structure and operating mechanism of evaluation activities. The "Overall Plan for Deepening Educational Evaluation Reform in the New Era" clearly pointed out that "educational evaluation is related to the direction of education development. What kind of evaluation baton is there, there is what kind of school-running orientation." For teachers, how they are evaluated is how they are more likely to develop. Under the guidance of actions such as "cleaning up the four merits" of the country, colleges and universities must also establish a diversified teacher evaluation system, build a multi-dimensional promotion channel, and respect the "letting a hundred flowers bloom" for teachers. Specifically, we should pay attention to the diversity and professionalism of evaluation subjects, take morality education as the basis of evaluation practice, adhere to student-oriented, establish quality-oriented education evaluation standards, and form a comprehensive education evaluation system [5].

\subsection{Simultaneous inheritance and innovation to perfect teacher incentive mechanism}

Colleges and universities should face the realistic dilemma of teacher incentives, break traditional constraints, innovate incentive methods, and truly achieve incentives to teachers. Teachers in colleges and universities are a group with distinctive characteristics. Incentives for this group not only require extensive use of external incentives such as salary incentives, assessment incentives and promotion incentives, as well as internal incentives such as innovation incentives, achievement incentives and social incentives, but also need to further graspe the individual characteristics and differences of the group on the incentive effect, so as to truly achieve effective incentives [6]. For example, academic reputation is an important recognition and evaluation of teachers by the academic community. However, under fierce academic competition, academic misconduct and deviant behaviors emerge one after another, which depletes the reputation of scholars and the entire academic circle. For this reason, we can try to construct an exploratory incentive mechanism framework design based on "signal-capital-psychology", rebuild college teachers' academic reputation incentives by releasing more "reputation" signals, and innovate incentive mechanisms such as establish a benign academic reputation ecology, and establish a reasonable teacher compensation system and so on [7].

\subsection{Cultivation of creativity and strengthening of social service awareness}

The creativity of college teachers is related to the quality of student training and social and economic development [3]. In the new era, personalized learning and differentiated learning have put forward higher requirements for the teaching design ability and innovation ability of college teachers. On the basis of understanding of students' study habits, hobbies, learning goals and other elements, teachers must have the ability to carry out personalized teaching design and teaching innovation. The ability to serve the economy and society is the vitality of colleges and universities. Business education is oriented to meet commercial circulation positions. Through teacher technological innovation and achievement transformation, it explores teacher resources, collects and evaluates teachers' technological level and achievement transformation application ability, and proposes measures to support enterprise technological innovation and path to enhance the educational brand and economic benefits. For this reason, it is necessary to continuously cultivate and improve teachers' innovative abilities. With the help of the dual channels of organizational education and selfeducation, project-based, combined, and integrated training models can be established, that is, the projectbased training led by project cooperated with schoolenterprise, the combined training led by internal training supplemented by external training, and the integrated training that integrates internal and external planning and follow-up dynamically [8]. In this process, the teachers' social service consciousness is continuously strengthened, so that the strengthening of consciousness and the improvement of ability influence each other, promote each other, and realize the spiral cultivation. 


\subsection{Consciousness and habit guidance as well as cultivation of a lifelong learning culture}

Learning culture is the sum of various learning characteristics acquired by a certain group in a certain period [9]. The construction of a lifelong learning culture requires a combination of "soft" and "hard". On the one hand, through the continuous improvement of policies and regulations that promote teachers' lifelong learning, a three-dimensional school-level incentive and restraint mechanism to promote teachers' lifelong learning has been established, and the "voluntary" barriers of self-directed learning logic have been broken [10]. On the other hand, rational use of information technology to consolidate and strengthen lifelong learning habits, transform consciousness into behavior, reconstruct the heterogeneous resources of self-directed learning logic [10]. The influence of technological evolution on learning culture runs throughout. With the advancement of modernization, the influence of technology on learning culture becomes more and more significant. Modern information technology has an obvious promotion effect on the construction of lifelong learning ability. It is rooted in the education information environment, so a new learning environment is gradually formed. More learning resources, richer learning platforms and environments all stimulate the enthusiasm of lifelong learning, the future of learning is no longer limited to a specific time and place, but transformed into a long-lasting, decentralized learning, further forming a life style and cultural mood [9]. In the process of combining "soft" and "hard", communities and other organizations can become carriers for the establishment, dissemination and consolidation of lifelong learning concepts and culture, and realize the growth of teachers driven by both their own transformation requirements and organizational development requirements.

\section{CONCLUSION}

The construction and cultivation of the core competencies of business teachers is related to the construction of business in the new era, and is essential to the cultivation of high-quality talents. Therefore, it is necessary to raise awareness and further explore more diversified cultivation paths.

\section{ACKNOWLEDGMENTS}

This research was financially supported by the "13th Five-Year Plan" of the Guangdong Provincial Higher Education Association 2020 Project (Grant NO. 20GQN36/20GYB38), Guangdong Province Educational Science "13th Five-Year Plan" 2020 Project(Grant NO. 2020GXJK169) and the Scientific Research and Innovation Team Building Project of
Neusoft Institute Guangdong (Grant NO. 2020XKYTD01).

\section{REFERENCES}

[1] Guangming Wang, Nan Zhang, Jian Li, Rui Yang, Sheng Zhang. The structure system and development suggestions of teachers' core literacy and ability $[\mathrm{J}]$.Chinese Journal of Education,2019(03):81-88.

[2] Zurong Zhong. On the key abilities of teachers in the new era[J].Teacher Development Research,2018,2(02):45-50.

[3] Yongwei Zhou, Hehua Fan. Construction and Empirical Research on the Evaluation System of University Teachers' Innovation Ability-Based on Factor Analysis[J]. Journal of Zhengzhou Institute of Aeronautical Industry Management (Social Science Edition), 2018,37(05):125-135.

[4] Hailong Lin. The innovation and practice of the intelligent manufacturing talent training model based on the "one horizontal and two vertical" inter-chain industry-education integration mechanism[J]. Higher Vocational Education (Journal of Tianjin Vocational University), 2019, 28(06) :41-46.

[5] Tianjun Cheng, Mingkai Zhang, Yuyou Qin, Yifan Sui, Haitao Zhou, Shuchao Zheng. Thoughts and directions on deepening the reform of education evaluation in the new era $[\mathrm{J}]$. China Audio-visual Education, 2021(07):1-12+21.

[6] Geng Teng, Huajun Yu, Yushi Jiang, Miao Miao. Research on the Incentive Structure Model of University Teachers and the Group Difference of Incentive Effects[J].Journal of Southwest Jiaotong University (Social Science Edition),2018,19(05):41-51.

[7] Xiaohui Jiang, Weiping Wang. Research on the Academic Reputation of University Teachers: An Exploratory Incentive Mechanism Design[J].China Higher Education Research,2021(04):42-47.

[8] Yuan Liu, Baoquan Men. Research on the training path of "double-qualified" teachers in higher vocational colleges from the perspective of core competence-Based on the "cone-shaped sixdimensional integrated" competency model[J]. Vocational Education Forum, 2021, 37( 07): 95101.

[9] Jing Li, Lei Liu. Technology-enabled higher education scale education and personalized training: logical necessity and practical mechanism[J]. China Audio-visual Education,2021(08):55-62. 
[10] Baoli Lu, Zhiye Zhang, Zunmin Wu. The essential thinking of constructing a lifelong learning education system that serves the whole peopleBased on the perspective of "self-directed learning"[J].China Distance Education,2021(08):1$11+39+76$. 